\title{
Preclinical evaluation of the antidiabetic effect of Eugenia jambolana seed powder in streptozotocin-diabetic rats
}

\author{
Correspondence \\ M.R.S.M. Pai \\ Department of Pharmacology \\ Kasturba Medical College \\ Mangalore 575001, Karnataka State \\ India \\ Fax: +91-824-242-8183 \\ E-mail: mrsmpai@hotmail.com
}

Research supported by Sri A.V.A. Trust (Regd), Shastri's

Pharmaceuticals, M.V. Shastri's \&

Sons, Mangalore, India, and Manipal

Academy of Higher Education, India.

Received October 22, 2003 Accepted January 6, 2005
1Department of Pharmacology, Kasturba Medical College, Mangalore, India

${ }^{2}$ Shastri's Pharmaceuticals, M.V. Shastri \& Sons, Mangalore, India

\begin{abstract}
The world is facing an explosive increase in the incidence of diabetes mellitus and cost-effective complementary therapies are needed. The effects of Eugenia jambolana, a household remedy for diabetes, were studied. Streptozotocin diabetic female albino Wistar rats weighing 150-200 $\mathrm{g}(\mathrm{N}=6)$ were fed E. jambolana seed powder $(250,500$ or $1000 \mathrm{mg} / \mathrm{kg}$ ) for 15 days. Diabetic rats fed 500 and $1000 \mathrm{mg} / \mathrm{kg}$ seed powder showed an increase in body weight on day 20 in relation to day $5(6 \pm 4.7,9 \pm 7.8 v s$ diabetic control -16 $\pm 7.1 \mathrm{~g}, \mathrm{P}<0.001)$, a decrease in fasting blood glucose $(75 \pm 11.9$, $123 \pm 14.4 v s$ diabetic control $-34 \pm 12.1 \mathrm{mg} / \mathrm{dl}, \mathrm{P}<0.001)$, a difference in post-treatment fasting and peak blood glucose $(38 \pm 11.9$, $36 \pm 14.2 v s$ diabetic control $78 \pm 11.9 \mathrm{mg} / \mathrm{dl}, \mathrm{P}<0.001)$, and a difference in liver glycogen $(50 \pm 6.8,52 \pm 7.5 v s$ normal control $90 \pm$ $6.6 \mu \mathrm{g} / \mathrm{g}$ of liver tissue, $\mathrm{P}<0.001)$. Tri-terpenoids, tannins, gallic acid, and oxalic acid were the chemical constituents detected in $E$. jambolana seed. The best results were obtained with an oral dose of $500 \mathrm{mg} / \mathrm{kg}$. Subacute toxicity studies with a single administration of 2.5 and $5.0 \mathrm{~g} / \mathrm{kg}$ seed powder showed no mortality or abnormality. These data on the antidiabetic effect of E. jambolana seed are adequate for approval of phase 2 clinical trials to evaluate this seed powder as complementary therapy in type 2 and type 1 diabetes.
\end{abstract}

Key words - Diabetes

- Eugenia jambolana seed

- Antidiabetic effect

- Preclinical data

- Liver glycogen

- Toxicity studies

\section{Introduction}

There is growing awareness of the role and practice of integrated medicine in the field of metabolic disorders. This is based in part on a flood of scientific data reported about medicinal plants including those with antidiabetic potential (1) and partly on the support provided for its practice by governmental agencies as well as the WHO (2). At our center there has been a compelling need to conduct phase 2 clinical trials in a select group of type 2 diabetes mellitus patients, combining an established oral hypoglycemic agent with Eugenia jambolana synonym Syzygium cumini, Syzygium jambolanum, 
family Myrtaceae, prescribed by Ayurveda, the ancient Indian form of medicine. Institutional Ethics Committee clearance for clinical trials requires as a prerequisite, data from preclinical animal studies and acute, subacute toxicity tests. We felt that the necessary preclinical data should be obtained from plants grown locally in view of contradictory reports about the use of a tea prepared from E. jambolana (3) and its lack of an antidiabetic effect on rats with streptozotocin (STZ)induced diabetes (4). Furthermore, there is a lack of scientific data on E. jambolana grown in the Western Ghats of coastal India though the seed is a household remedy and is prescribed in these parts of India by Ayurveda medicine for diabetes mellitus. It is also well known that the chemical constituents isolated from the plant can vary according to humidity, soil, climate, and geography.

The primary objective of the study was to examine the antidiabetic potential of subchronic oral administration of E. jambolana seed powder in rats with STZ-induced diabetes. The results of the preclinical study could prove useful for phase 2 clinical trials in which the morbidity and mortality of diabetes mellitus complicated by the side effects of drug-induced hypoglycemia may be reduced by the practice of integrated medicine.

\section{Material and Methods}

\section{Plant material and treatment preparation}

The seed powder of E. jambolana was obtained from plants grown in the herbarium of an Ayurvedic establishment in the Dakshina Kannada district of Karnataka State located in the Western Ghats of coastal India. The plant was identified by Dr. Kakunje Gopalkrishna Bhat and authenticated material was deposited in the Herbarium of the Botanical Survey of India in Pune. The seeds were collected during the month of April; $500 \mathrm{~g}$ of seeds dried in sunlight yielded 450 $\mathrm{g}$ of $E$. jambolana seed powder.

\section{Animals, treatment and chemical analysis}

Female albino Wistar rats from the same colony weighing 150-200 g were obtained from the central animal house of Kasturba Medical College, Mangalore. They were housed in individual cages under natural light and dark cycles at a temperature of $28 \pm 4^{\circ} \mathrm{C}$, given a standard pellet diet and water $a d$ libitum and were acclimatized for 3 days before the beginning of the experiment. The animals were randomized to the following groups containing 6 rats each: group I, normal control; group II, diabetic control; group III received glibenclamide, $5 \mathrm{mg} / \mathrm{kg}$, by gavage; groups IV, V, and VI received $E$. jambolana seed powder, 250, 500, $1000 \mathrm{mg} /$ $\mathrm{kg}$ by gavage, respectively. Since the seed powder was poorly soluble in water, a suspension was prepared in $2 \%$ gum acacia. All animals were deprived of food for at least 12 $\mathrm{h}$ but had free access to drinking water. Animals in group I received citrate buffer intraperitoneally. Animals in groups II, III, $\mathrm{IV}, \mathrm{V}$, and VI received STZ, $50 \mathrm{mg} / \mathrm{kg}$, in freshly prepared $10 \mathrm{mM}$ citrate buffer, $\mathrm{pH}$ 4.5, intraperitoneally. Animals were kept fasted for $3 \mathrm{~h}$ after injection, returned to their cages and given food and water ad libitum. The mean weight of the animals in each group was recorded on days $1,5,10,15$, and 20. Daily fluid intake was recorded and mean fluid intake by the animals in each group was tabulated on days $1,5,10,15$, and 20. On day 5 after STZ administration, fasting blood glucose (FBS) was measured (5) and the glucose tolerance test (GTT) performed after an overnight fast. Blood was collected from the inner canthus of the eye using capillary tubes. Only animals whose FBS was more than thrice the normal value were included in the study ( $\mathrm{N}=6$ per group). The GTT was performed after a glucose challenge of $2.5 \mathrm{~g} / \mathrm{kg}$ body weight given orally by gastric intubation. Blood glucose was measured at 30-, 60- and 120-min intervals. Glibenclamide and E. jambolana were given 
intragastrically once a day at a fixed time interval each day for 15 days. The animals were fasted $30 \mathrm{~min}$ before and after treatment to ensure maximum bioavailability. Animals in the untreated groups were forcefed $2 \%$ gum acacia suspension. On day 20 , after STZ injection, FBS and GTT were performed after an overnight fast. On day 21 , fasting animals were sacrificed by cervical dislocation and liver glycogen was estimated with anthrone reagent (6).

\section{Statistical analysis}

Kruskal-Wallis one-way analysis of variance was used to compare the mean changes in metabolic parameters of the 6 groups. When a significant difference was detected between groups, the multiple comparison criterion was used for pairwise group comparison. ANOVA for repeated measures or Friedman's test was used to compare the differences between the five periods of observation. The level of significance was set at $\mathrm{P}<0.05$.

The experimental protocol was approved by the Institutional Ethics Committee.

\section{Results and Discussion}

Table 1 summarizes the effect of STZ and treatments on mean body weight and fluid intake. A statistically significant increase in body weight was observed on days 10 and 15 of treatment with glibenclamide and E. jambolana, with 500 and $1000 \mathrm{mg} / \mathrm{kg}$ body weight.

Table 2 summarizes the results of the GTT. The FBS was increased up to 4.5 times the normal control value on day 0 of treatment in groups II, III, IV, V, and VI, and was significantly reduced in all treatment groups 15 days after treatment. The peak blood glucose level observed in all groups occurred at $30 \mathrm{~min}$. In the normal control and treatment groups, 15 days after treatment, the blood glucose levels were reduced to nearly fasting levels at $2 \mathrm{~h}$. However, in the diabetic control and treatment groups, at day 0 of treatment, the blood glucose levels remained elevated at $2 \mathrm{~h}$. On day 0 of treatment the difference between fasting and peak blood glucose levels ranged from 65 to $100 \mathrm{mg} / \mathrm{dl}$ in groups II, III, IV, V, and IV, and was only $25 \mathrm{mg} / \mathrm{dl}$ in group I. On day 15 of treatment the difference between fasting and peak blood glucose levels was $53 \mathrm{mg} / \mathrm{dl}$ in group III, $50 \mathrm{mg} / \mathrm{dl}$ in group IV, $38 \mathrm{mg} / \mathrm{dl}$ in group $\mathrm{V}$, and $36 \mathrm{mg} / \mathrm{dl}$ in group VI, and was $26 \mathrm{mg} /$ $\mathrm{dl}$ in group I and $78 \mathrm{mg} / \mathrm{dl}$ in group II. In groups IV, V, and VI the percent reductions in pre-treatment versus post-treatment fast-

Table 1. Effect of Eugenia jambolana seed powder on body weight $(\mathrm{g})$ and fluid intake $(\mathrm{ml} / 24 \mathrm{~h})$ of streptozotocin-diabetic rats.

\begin{tabular}{|c|c|c|c|c|c|c|c|c|c|c|}
\hline \multirow[t]{3}{*}{ Group/Treatment } & \multicolumn{10}{|c|}{ Days after STZ injection (days after treatment) } \\
\hline & \multicolumn{2}{|c|}{0 days } & \multicolumn{2}{|c|}{5 days ( 0 days) } & \multicolumn{2}{|c|}{10 days (5 days) } & \multicolumn{2}{|c|}{15 days (10 days) } & \multicolumn{2}{|c|}{20 days ( 15 days) } \\
\hline & $\begin{array}{l}\text { Body } \\
\text { weight }\end{array}$ & $\begin{array}{l}\text { Fluid } \\
\text { intake }\end{array}$ & $\begin{array}{l}\text { Body } \\
\text { weight }\end{array}$ & $\begin{array}{l}\text { Fluid } \\
\text { intake }\end{array}$ & $\begin{array}{c}\text { Body } \\
\text { weight }\end{array}$ & $\begin{array}{l}\text { Fluid } \\
\text { intake }\end{array}$ & $\begin{array}{l}\text { Body } \\
\text { weight }\end{array}$ & $\begin{array}{l}\text { Fluid } \\
\text { intake }\end{array}$ & $\begin{array}{l}\text { Body } \\
\text { weight }\end{array}$ & $\begin{array}{l}\text { Fluid } \\
\text { intake }\end{array}$ \\
\hline I Normal control & $188 \pm 4$ & $38 \pm 2$ & $191 \pm 4$ & $38 \pm 2$ & $193 \pm 4$ & $38 \pm 2$ & $195 \pm 4$ & $37 \pm 2$ & $198 \pm 4$ & $39 \pm 2$ \\
\hline II Diabetic control & $182 \pm 8$ & $36 \pm 2$ & $155 \pm 6^{a}$ & $38 \pm 2$ & $148 \pm 8^{a}$ & $43 \pm 2$ & $143 \pm 9^{a}$ & $46 \pm 2$ & $139 \pm 8^{a}$ & $50 \pm 2$ \\
\hline III Diabetic + glibenclamide $5 \mathrm{mg} / \mathrm{kg}$ & $189 \pm 6$ & $35 \pm 2$ & $163 \pm 6$ & $38 \pm 2$ & $170 \pm 5$ & $40 \pm 2$ & $172 \pm 5^{b}$ & $39 \pm 2$ & $178 \pm 5^{b}$ & $38 \pm 2$ \\
\hline IV Diabetic + EJ 250 mg/kg & $182 \pm 11$ & $28 \pm 2$ & $166 \pm 11$ & $30 \pm 2$ & $165 \pm 9$ & $33 \pm 2$ & $161 \pm 10$ & $33 \pm 2$ & $154 \pm 11$ & $33 \pm 2$ \\
\hline$V$ Diabetic + EJ $500 \mathrm{mg} / \mathrm{kg}$ & $183 \pm 6$ & $29 \pm 2$ & $165 \pm 3$ & $34 \pm 2$ & $169 \pm 4$ & $36 \pm 2$ & $170 \pm 5^{b}$ & $33 \pm 2$ & $171 \pm 5^{b}$ & $35 \pm 2$ \\
\hline VI Diabetic + EJ 1000 mg/kg & $174 \pm 8$ & $30 \pm 2$ & $157 \pm 6$ & $32 \pm 2$ & $162 \pm 7$ & $32 \pm 2$ & $162 \pm 8^{b}$ & $31 \pm 2$ & $166 \pm 7^{b}$ & $31 \pm 2$ \\
\hline
\end{tabular}

Data are reported as means \pm SEM for groups of 6 animals each. EJ = Eugenia jambolana. STZ = streptozotocin.

ap $<0.001$ compared to normal control; bP $<0.001$ compared to diabetic control (Kruskal-Wallis analysis of variance). 
Table 2. Hypoglycemic effect of Eugenia jambolana seed powder on blood glucose (mg/dl) of streptozotocin-diabetic rats.

\begin{tabular}{|c|c|c|c|c|c|c|c|c|c|c|}
\hline \multirow{4}{*}{ Group } & \multirow{4}{*}{ Fasting } & \multicolumn{7}{|c|}{ Days after STZ injection (days after treatment) } & \multirow{2}{*}{\multicolumn{2}{|c|}{$\frac{\text { Percent fall in blood glucose }}{20 \text { days (15 days) }}$}} \\
\hline & & \multirow{2}{*}{\multicolumn{3}{|c|}{$\begin{array}{c}5 \text { days ( } 0 \text { days) } \\
\text { Glucose tolerance test }\end{array}$}} & \multirow{3}{*}{ Fasting } & \multirow{2}{*}{\multicolumn{3}{|c|}{$\begin{array}{c}20 \text { days (15 days) } \\
\text { Glucose tolerance test }\end{array}$}} & & \\
\hline & & & & & & & & & \multirow[t]{2}{*}{ Fasting } & \multirow{2}{*}{$\begin{array}{l}\text { Peak level } \\
\text { in GTT }\end{array}$} \\
\hline & & $30 \mathrm{~min}$ & $60 \mathrm{~min}$ & $120 \min$ & & $30 \mathrm{~min}$ & $60 \mathrm{~min}$ & $120 \mathrm{~min}$ & & \\
\hline । & $50 \pm 7.1$ & $75 \pm 9.5$ & $66 \pm 8.7$ & $60 \pm 7.7$ & $54 \pm 6.8$ & $80 \pm 9.6$ & $70 \pm 10.7$ & $65 \pm 9.1$ & & \\
\hline 11 & $243 \pm 11.1^{\mathrm{a}}$ & $340 \pm 10.6^{a}$ & $295 \pm 9.5^{a}$ & $280 \pm 8.8^{a}$ & $277 \pm 12.6$ & $355 \pm 10.1$ & $330 \pm 12.8$ & $300 \pm 10.1$ & & \\
\hline III & $264 \pm 10.6^{a}$ & $350 \pm 11.3^{a}$ & $320 \pm 9.7^{a}$ & $310 \pm 9.7^{a}$ & $122 \pm 12.6^{b}$ & $175 \pm 11.6^{b}$ & $140 \pm 12.6^{b}$ & $130 \pm 10.7^{b}$ & -54 & -50 \\
\hline IV & $258 \pm 13.7^{a}$ & $345 \pm 12.6^{a}$ & $315 \pm 10.6^{a}$ & $285 \pm 9.6^{a}$ & $225 \pm 14.5^{b}$ & $275 \pm 11.1^{b}$ & $250 \pm 12.1^{b}$ & $230 \pm 10.5^{b}$ & -13 & -20 \\
\hline V & $247 \pm 10.7^{a}$ & $330 \pm 10.8^{a}$ & $290 \pm 10.7^{a}$ & $275 \pm 9.1^{a}$ & $172 \pm 12.8^{b}$ & $210 \pm 10.8^{b}$ & $200 \pm 13.6^{b}$ & $180 \pm 11.5^{b}$ & -30 & -36 \\
\hline VI & $267 \pm 13.3^{a}$ & $335 \pm 10.1^{a}$ & $310 \pm 10.8^{a}$ & $290 \pm 9.6^{a}$ & $144 \pm 14.6^{b}$ & $180 \pm 10.9 b$ & $160 \pm 14.7^{b}$ & $155 \pm 11.6^{b}$ & -46 & -46 \\
\hline
\end{tabular}

See Tables 1 and 3 for explanation of groups and treatments. Data are reported as means \pm SEM for groups of 6 animals each. EJ $=$ Eugenia jambolana. STZ $=$ streptozotocin.

ap $<0.001$ compared to normal control; ${ }^{b} \mathrm{P}<0.05$ compared to diabetic control (Kruskal-Wallis analysis of variance).

Table 3. Effect of Eugenia jambolana seed powder on liver glycogen of streptozotocin-diabetic rats.

\begin{tabular}{clc}
\hline Group & Treatment & $\begin{array}{c}\text { Liver glycogen } \\
(\mu \mathrm{g} / \mathrm{g} \text { of tissue })\end{array}$ \\
\hline I & Normal control & $90 \pm 6.6$ \\
II & Diabetic control & $30 \pm 7.6$ \\
III & Diabetic + glibenclamide $5 \mathrm{mg} / \mathrm{kg}$ & $65 \pm 6.5^{\mathrm{a}}$ \\
IV & Diabetic + EJ $250 \mathrm{mg} / \mathrm{kg}$ & $35 \pm 5.6^{\mathrm{a}}$ \\
V & Diabetic + EJ $500 \mathrm{mg} / \mathrm{kg}$ & $50 \pm 6.8^{\mathrm{a}}$ \\
VI & Diabetic + EJ $1000 \mathrm{mg} / \mathrm{kg}$ & $52 \pm 7.5^{\mathrm{a}}$ \\
\hline
\end{tabular}

Data are reported as means \pm SEM for groups of 6 animals each on day 21 (15 days after treatment). EJ = Eugenia jambolana.

ap $<0.001$ compared to normal control (Kruskal-Wallis analysis of variance). ing and peak blood glucose levels were 13, 30,46 and 20,36, 46, respectively.

Table 3 summarizes the liver glycogen content. There was a statistically significant increase in liver glycogen in all treatment groups which, however, was not equivalent to the normal control.

The present study shows that the antidiabetic effect of $E$. jambolana seed powder was better with $500 \mathrm{mg} / \mathrm{kg}$ body weight, as shown by an increase in mean body weight, a post-treatment difference between fasting and peak blood glucose levels, the percent reduction in pre-treatment versus post-treatment fasting and peak blood glucose levels, and elevation in liver glycogen values. The seed powder at a dose of $1000 \mathrm{mg} / \mathrm{kg}$ body weight did not show a proportional improvement in the above metabolic parameters, suggesting that an increased concentration of active ingredients is not always proportionally beneficial $(7,8)$ and can be associated with adverse effects (4) when used as complementary therapy to established hypoglycemic agents. The hypoglycemic activity of E. jambolana seed powder has been detected in studies conducted in places other than the Western Ghats of India. In most studies on seed powder, the dose used was $1 \mathrm{~g} / \mathrm{kg}$ body weight or higher $(7,9)$, or was administered as a single dose of $200 \mathrm{mg} / \mathrm{kg}$ (10), or as fixed multiple doses of 100, 200, or $400 \mathrm{mg}$ (11). The present study clearly defines a dose-response effect on glycemia and liver glycogen for E. jambolana seed powder administered according to body weight to STZ-induced diabetic female rats. HPLC chromatograms of E. jambolana 
seed powder extracted with dichloromethane showed seven peaks. Tri-terpenoids, tannins, gallic acid, and oxalic acid were detected using suitable chemical tests. Alkaloids were present in small amounts. Similar constituents have been detected in previous studies $(12,13)$. Further studies on the extraction and purification of each component will help identify the active ingredients.

Toxicity studies were carried out as a requirement for Ethics Committee clearance. The animals were observed for 14 days, with no evidence of mortality or abnormalities (Table 4). Blood glucose levels decreased only by $11-15 \% v s$ the normal controls after the GTT, in contrast to the study of Achrekar et al. (14), in which a $34 \%$ decrease in blood glucose levels was observed in normal rats 5 days after treatment with $50 \mathrm{~g}$ of seed powder homogenized in $100 \mathrm{ml}$ water. This shows that E. jambolana possibly acts as a hypoglycemic agent by increasing insulin levels $(14,15)$ rather than just as an antihyperglycemic agent. Glibenclamide, tested at doses of $0.25,0.5$, and $1.3 \mathrm{mg} / \mathrm{kg}$, did not promote any antihyperglycemic activity in STZ-diabetic rats in the pilot study.

The experimental STZ-diabetes model usually involves type 1 diabetes. However, in the present study, at the dose of STZ used, the model probably involved type 2 diabetes and some functioning $\beta$ cells of islets of Langerhans were present because: a) untreated diabetic controls survived in spite of increasing FBS and GTT blood glucose levels as observed on day 15 of treatment; b) a response to treatment was observed in group III without insulin treatment. The measurements of the end points of insulin activity, i.e., FBS and GTT blood glucose and liver glycogen levels, in this study suggest that $E$. jambolana seed promote the release of insulin, a finding also reported by Achrekar et al. (14) after measuring insulin levels in vivo and in vitro. A dose-dependent in vitro reduction in insulin degradation (14) was also seen. Thus, we conclude that the seed
Table 4. Effect of a single oral dose of Eugenia jambolana seed powder on the glucose tolerance test.

\begin{tabular}{lllll}
\hline & \multicolumn{4}{c}{ Blood glucose (mg/dl) } \\
\cline { 2 - 5 } & Fasting & \multicolumn{3}{c}{ Glucose tolerance test } \\
\cline { 2 - 4 } & & $30 \mathrm{~min}$ & $60 \mathrm{~min}$ & $120 \mathrm{~min}$ \\
\hline EJ $2.5 \mathrm{~g} / \mathrm{kg}$ body weight & $48 \pm 4.1$ & $72 \pm 2.1$ & $65 \pm 5$ & $59 \pm 6$ \\
EJ $5.0 \mathrm{~g} / \mathrm{kg}$ body weight & $46 \pm 2.1$ & $68 \pm 4.1$ & $61 \pm 2.1$ & $56 \pm 3$
\end{tabular}

Data are reported as means \pm SEM for groups of 6 normal animals each, 14 days after treatment. EJ = Eugenia jambolana.

powder should be evaluated in a) type 2 diabetes, not as monotherapy on account of inadequate activity (Tables 2 and 3), but complementing established oral hypoglycemic agents, reducing their established dosing regimen which would reduce their side effects, and in b) type 1 diabetes as a treatment complementary to insulin.

Diabetes is now considered to be a vascular disease. The cost of treating the microvascular component (retinopathy, nephropathy and neuropathy) and controlling the macrovascular component is a serious drain on health resources, particularly in developing countries. It is expected that by the year 2025 India will have 57.2 million diabetics (one sixth of the world total) (16). Besides the prevention strategies proposed (16), the use of cost-effective therapies goes a long way towards the aforementioned goal. The authors contend that patient preferences for therapies are guided by cultural heritage and by the natural environment of the region they live in. The results of this preclinical and toxicity study provide the necessary data for phase 2 clinical trials in type 2 and type 1 diabetes with E. jambolana seed powder as an 'add on' therapy to established oral hypoglycemic agents and/or insulin.

\section{Acknowledgments}

The authors thank the late Dr. M.S. Shastri who co-authored the paper and who 
died during the course of the study; Dr. Kakunje Gopalakrishna Bhat, Professor and Head, Department of Botany, Poornaprajna College, Udupi, for identification and authentication of E. jambolana; Ms. Asha Kamath,
Department of Community Medicine, Kasturba Medical College, Manipal, and Dr. Richard Gonsalves, Department of Chemistry, St. Aloysius College, Mangalore, for a critical analysis of the manuscript.

\section{References}

1. Grover JK, Yadav S \& Vats V (2002). Medicinal plants of India with anti-diabetic potential. Journal of Ethnopharmacology, 81: 81-100.

2. World Health Organization (1980). WHO Expert Committee on Diabetes Mellitus Second Report. Technical Report Series, 646: 61.

3. Teixeira CC, Fuchs FD, Blotta RM, Da Costa AP, Mussnich DG \& Ranquetat GG (1992). Plants employed in the treatment of diabetes mellitus: results of an ethnopharmacological survey in Porto Alegre, Brazil. Fitoterapia, 63: 320-322.

4. Pepato MT, Folgado VBB, Kettelhut IC \& Brunetti IL (2001). Lack of antidiabetic effect of a Eugenia jambolana leaf decoction on rat streptozotocin diabetes. Brazilian Journal of Medical and Biological Research, 34: 389-395.

5. Trinder $P$ (1969). Determination of glucose using glucose oxidase with an alternative oxygen acceptor. Annals of Clinical Biochemistry, 6: 24-27.

6. Hassid WZ \& Abraham S (1960). Determination of glycogen by modified Pfliiger method. In: Sydney PC \& Nathan OK (Editors), Methods in Enzymology. Vol. 111. 2nd edn. Academic Press, New York, 34-36.

7. Prince PSM, Menon VP \& Pari L (1998). Hypoglycemic activity of Syzigium cumini seeds: effect on lipid peroxidation in alloxan diabetic rats. Journal of Ethnopharmacology, 61: 1-7.

8. Sharma SB, Nasir A, Prabhu KM, Murthy PS \& Dev G (2003). Hypoglycemic and hypolipidemic effect of ethanolic extract of seeds of Eugenia jambolana in alloxan-induced diabetic rabbits. Journal of Ethnopharmacology, 85: 201-206.

9. Kedar P \& Chakrabarti CH (1983). Effects of jambolan seed treat- ment on blood sugar, lipids and urea in streptozotocin induced diabetes in rabbits. Indian Journal of Physiology and Pharmacology, 27: 135-140.

10. Grover JK, Vats V, Rathi SS \& Dawar R (2001). Traditional Indian anti-diabetic plants attenuate progression of renal damage in streptozotocin induced diabetic mice. Journal of Ethnopharmacology, 76: 233-238.

11. Vats V, Grover JK, Tandon N, Rathi SS \& Gupta N (2001). Treatment with extracts of Momordica charantia and Eugenia jambolana prevents hyperglycemia and hyperinsulinemia in fructose fed rats. Journal of Ethnopharmacology, 76: 139-143.

12. The Himalaya Drug Company (2004). Himalaya Herbal Healthcare. Herbal Monograph page [http://www.himalayahealthcare.com/ herbfinder/h_syzygi.htm]. Accessed July 20, 2004.

13. Pioneer Enterprise (2004). Phytonutrients and Standardized Herbal extracts page [http://www.pioneerherbs.com/eugenia_jambolana. htm]. Accessed July 20, 2004.

14. Achrekar S, Kaklij GS, Pote MS \& Kelkar SM (1991). Hypoglycemic activity of Eugenia jambolana and Ficus bengalensis: mechanism of action. In Vivo, 5: 143-148.

15. Bansal R, Ahmad N \& Kidwai JR (1981). Effect of oral administration of Eugenia jambolana seeds and chlorpropamide on blood glucose level and pancreatic cathepsin B in rat. Indian Journal of Biochemistry and Biophysics, 18: 377.

16. Pradeep $R$ \& Mohan $V$ (2002). The changing scenario of the diabetes epidemic: implications for India. Indian Journal of Medical Research, 116: 121-132. 